\title{
Establishing the link between urban land cover change and the proliferation of aquatic hyacinth (Eichhornia crassipes) in Harare Metropolitan, Zimbabwe
}

\author{
Timothy Dube $^{\mathrm{a}, *}$, Mbulisi Sibanda $^{\mathrm{b}}$, Victor Bangamwabo ${ }^{\mathrm{b}}$, Cletah Shoko ${ }^{\mathrm{b}}$ \\ a Department of Earth Sciences, University of the Western Cape, Private Bag X17, Bellville, 7535, South Africa \\ ${ }^{\mathrm{b}}$ Discipline of Geography, School of Agricultural, Earth and Environmental Sciences, University of KwaZulu-Natal, P/Bag X01, Scottsville, Pietermaritzburg, 3209, South \\ Africa
}

\section{A R T I C L E I N F O}

\section{Keywords:}

Baseline data

Freshwater ecosystems

Harare metropolitan city

Urban expansion

Remote sensing

Water quality

\begin{abstract}
A B S T R A C T
Urban growth is a key process affecting the functioning of natural ecosystems, and consequently the global landsurface process. This work aimed at establishing the link between land cover changes around Harare Metropolitan city and the proliferation of aquatic hyacinth (Eichhornia crassipes) in Lake Chivero. Remotely sensed Landsat series acquired in the year 1973, 1981, 1994, 1998, 2008, 2009 and 2014 was used. Image classification was implemented to map the associated changes over time using discriminant analysis algorithm. Derived thematic land cover maps showed that agricultural land increased from $2 \%$ in 1973 to a $5 \%$ in 1981 reaching up to 30\% in 2014, whereas the city's land area significantly ( $\mathrm{p}<0.05)$ increased between 1973 and 1994. However, water hyacinth constantly increased over time. The spatial and temporal resolution of Landsat images detected land cover changes and the proliferation of aquatic hyacinth (Eichhornia crassipes) in the Lake Chivero over time.
\end{abstract}

\section{Introduction}

Urban growth is a key process affecting global climate change, due to the modification of the existing functioning of natural ecosystems, and consequently the global land-surface process. In the past three decades, the world population has drastically increased, with half of it currently living in cities. The highest rate of urbanization in the developing world, are largely linked to urban economic growth, rural migrations, amongst other factors. Consequently, urban development management strategies have increased in their scope and complexity (Caldwell, 1969; Fields, 1975; Gaidzanwa, 2016; Mberu, 2016; Muchadenyika and Williams, 2016). Cohen (2006), has, however, reported that the speed and sheer scale of urban growth in third world cities surpass their ability to deliver sufficient basic services to their citizens, thus urban management remains a serious challenge today. Urban growth trends also imply a high land demand for the new settlements and agriculture to meet population food needs. Global statistics indicate that more than two-thirds of the urban population is below the poverty line (Chant and Datu, 2015; Duque et al., 2015; Satterthwaite, 2003; Tacoli et al., 2015). Seventy percent of cities' inhabitants live in slums (Bhattacharya et al., 2012; Chen et al., 2013; Cohen, 2006; Von Braun, 2007; Wu et al., 2013), with inadequate water and sanitation infrastructures, poor health conditions and a lack of social cohesion or individual rights. This situation has an effect on the surrounding natural environment; inducing greater strains on the countries' already stressed resources (Bhattacharya et al., 2012; Booth et al., 2013; Chawira et al., 2013; Dlamini et al.; Dube et al., 2014; Mberu, 2016).

Literature shows that urban expansion results in the replacement of natural land covers for impervious surfaces, inducing an increase in the surface temperature (Adam et al., 2014; Booth et al., 2013; Chawira et al., 2013; Mushore et al., 2016; John Odindi et al., 2012), modifying land-surface energy processes (Carlson and Arthur, 2000; Clark et al., 2010). Therefore, reliable, up-to-date and detailed urban land use and the land cover spatial information is, therefore, required to ensure an efficient land use planning, so as to minimize the alterations in the biophysical environment. In aquatic environments, especially in developing countries were the poor waste and sewage disposal is a common phenomenon. Urban growth can lead to water quality deterioration and lake eutrophication (Kibena et al., 2014; Masamba and Mazvimavi, 2008; Palamuleni et al., 2011; Wear et al., 1998). Waste and leachates become the primary nutrient source for the aquatic invasive species, water hyacinth (Eichhornia crassipes). The United States of America use over hundred million US dollars per year in the removal (by means of mechanical and chemical processes) of these invasive species from freshwater bodies (Hestir et al., 2008; Parochetti et al.,

\footnotetext{
* Corresponding author.

E-mail address: tidube@uwc.ac.za (T. Dube).
} 


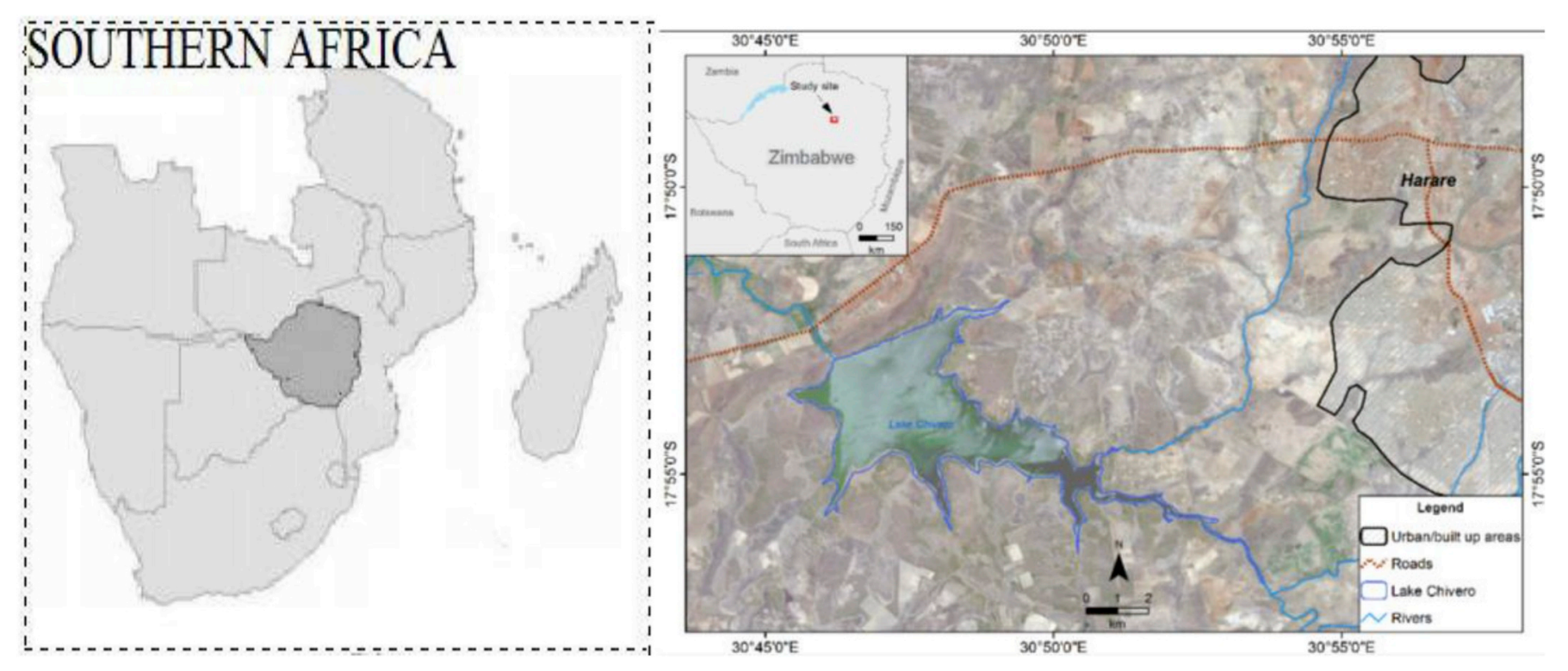

Fig. 1. Location of the study area.

2008).

In Zimbabwe, particularly Harare metropolitan city, most inland waterbodies are facing severe water pollution, accompanied by high rates of invasive species proliferation. Previous work has established that Lake Manyame and Chivero stand as the most polluted sources of the city's water resources, with more than half of their surface covered with invasive water weeds (Chawira et al., 2013; Shekede et al., 2008). Field surveys have shown that most of the pollution comes from the improper and illegal disposal of domestic and industrial waste, resulting from infrequent garbage collection, as well as from the use of inorganic fertilisers. Accurate and reliable information on land use and land cover dynamics in urban cities is therefore crucial for developing robust urban monitoring and planning protocols, and for devising wellinformed mitigation plans. To be able to develop a robust and appropriate policy document, relevant information at various spatial (from detail to regional ones) and temporal scales, is necessary for decision making, up-to-date land use and land cover national databases are required. This information can assist city authorities and other interested stakeholders to accurately project and design urban growth strategies, and also monitor the associated impacts on the environment.

Previous studies show that land use and land cover mapping accuracy depends on the mapping scale and the satellite images' spatial, temporal and spectral resolution used (Mushore et al., 2016). Urban land cover and land use changes have been usually mapped, using satellite data with varying characteristics, mostly medium to coarse spatial resolution images (Clark et al., 2010; Langner et al., 2007; Loveland et al., 1991). Although urban land cover can be detected, using these datasets, their coarse spatial resolution (300-1000 m) hinders their use in smaller urban areas, such as Harare metropolitan area $\left(60.6 \mathrm{~km}^{2}\right)$. Even when high spatial or spectral resolution data (e.g. Worldview satellite or hyperspectral data) would be more suitable for these areas, their high cost and low temporal resolution is key for monitoring land changes, also hinder their use in this study (Adam et al., 2014).

In comparison, the medium-resolution 30-m Landsat satellites series data (since its inception in 1972 to the present) provides the most attractive and suitable data-source required for mapping the extent of land use and land cover changes in these urban areas (Mushore et al., 2016). Previous studies, using Landsat images for mapping urban LULC changes so far, focussed on single date mapping. (Gumindoga et al., 2014; Mushore et al., 2016) and this information is not enough to establish the changes. Due to the open access nature of the Landsat archive, it is possible to take full advantage of this data to reconstruct the long-term history of urban expansion. Landsat series data have demonstrated its strength for mapping vegetation cover, urban heat island (Mushore et al., 2016; JO Odindi et al., 2015), land cover changes and water accounting (Cletah Shoko et al., 2015; C. Shoko et al., 2016). However, most of the previous studies were based on long temporal intervals (10-year time step) with a categorical thematic scale, hence unable to reveal the complete changes over time. Besides, none of these studies have attempted to link urban growth to the proliferation of invasive water weeds in the surrounding freshwater ecosystems. The objective of this study was to establish possible relations between urban changes and the proliferation of the aquatic hyacinth (Eichhornia crassipes) in Lake Chivero.

\section{Materials and methods}

\subsection{Study area}

Remotely sensed data were used to analyze LULC changes and their implications on the freshwater ecosystems. The study was conducted over one of the main water sources for Zimbabwe capital city: Lake Chivero (formerly Lake McLlwaine). Lake Chivero is located on the central plateau at an altitude ranging between 1300 and $1600 \mathrm{~m}$, with a surface area of $\sim 6100$ ha. This Lake does not only supply water to a variety of human activities (i.e. human consumption, irrigation, construction, etc); but it also provides habitat to a number of endogenous birds, fishes and ungulates. The study hypothesised that population growth can alter the state of this freshwater ecosystem. Nowadays the lake is inhabited by invasive plants, such as water hyacinth (Eichhornia crassipes), due to the excess effluent into the system (see Fig. 1).

\subsection{Remotely sensed data}

To determine LULC dynamics over the metropolitan Harare area and to monitor the changes, seven Landsat images covering a period of 40 years (1973, 1981, 1994, 1998, 2008, 2009 and 2014) were used. Detailed information on the selected images is provided in Table 1 . The criterion used to select the images was the cloud cover. For this study images acquired during the dry season were used. The Landsat image bands were layer-stacked in ENVI 5.1 software, using the nearest neighbourhood resampling technique. The selected images were then corrected for atmospheric effects, using the FLAASH model. 
Table 1

Detailed information on the selected Landsat images.

\begin{tabular}{lll}
\hline Year & Acquisition year/Day/Month & Sensor \\
\hline 1973 & $1973 / 24 / 8$ & Landsat 1 \\
1981 & $1981 / 13 / 4$ & Landsat 3 \\
1994 & $1994 / 24 / 9$ & Landsat TM 5 \\
1998 & $1998 / 30 / 8$ & Landsat TM 5 \\
2008 & $2008 / 25 / 6$ & Landsat TM 5 \\
2009 & $2009 / 14 / 6$ & Landsat TM 5 \\
2014 & $2014 / 30 / 4$ & Landsat 8 OLI \\
\hline
\end{tabular}

Radiometric correction was conducted following the method by X. Pons et al. (2014) and Xavier Pons and Solé-Sugrañes (1994). Landsat images were acquired in Digital Number (DN) value format and then calibrated to radiance $\left[\mathrm{Wm}^{-2} \mathrm{sr}^{-1} \mu \mathrm{m}^{-1}\right]$, based on the method by Chander et al. (2009).

\subsection{Field surveys}

Field surveys, aerial photographs and Google Earth data were used to validate image classification results both historic and current. This was based on the usual practice in literature where historical images are validated using topo-maps. Burned areas, cultivated, areas, grasslands, shrub/indigenous forest, urban areas, water bodies and water hyacinth land cover types were considered in this study. During the field surveys, locations of land cover types of interest were recorded, using a handheld Global Positioning System (GPS) to an accuracy of less than $5 \mathrm{~m}$. These locations were imported into a geographic information system and converted into point maps, also compared with points generated from the aerial photographs. The point maps were then overlaid on satellite images and used to extract radiances for each land cover type. The same process was implemented on all images considered for this study. The extracted point data were then randomly split into training data (70\%) and testing data (30\%).

\subsection{Statistical analysis and classification}

\subsubsection{Analysis of variance}

Analysis of variance test (ANOVA) was used to determine if there were significant differences amongst the radiance of the different land cover types. Dunnett's post hoc tests were then applied to assess whether significant differences could be established between water hyacinth and different land cover types. Furthermore, they were used as a pre-filter to trim out redundant wavebands. Then for land cover classification purposes, only the bands that yielded a significant difference between the types were used.

\subsubsection{Discriminant analysis}

To differentiate and classify different land cover types we used Discriminant Analysis, which applies a function based on the squared distances between class types, providing cross-validated results. To design the discriminant functions the DA method groups the wavelengths into components (latent factors) that are then used to discriminate different land cover types. This analysis provides eigenvalues that determine the robustness of each specific cluster of wavebands in discriminating different cover types. The contribution of each waveband in a component is derived, using eigenvectors (variable scores), thus the wavebands that better discriminated the land cover types were the ones exhibiting higher variable scores. During the classification process, the DA algorithm first administered statistics, such as the Box test (Chi-square asymptotic approximation), Box test (Fisher's F asymptotic approximation), Mahalanobis distances, Wilks' Lambda test (Rao's approximation) and Kullback's test. The two Box tests and the Kullback's test were conducted to test whether the covariance matrices are equal between the groups. Specifically, the HO hypothesis we tested was that the within-class covariance matrices of different land cover classes were equal whereas $\mathrm{H} 1$ tested that the within-class covariance matrices of different land cover classes were different with alpha at 0.05. The Wilks' Lambda test, as well as the Mahalanobis distances, were conducted to tested whether the vector of the means for the various land cover groups was equal or not (alpha at 0.05).

As a prerequisite, different group covariances that did not exhibit any significant differences were not considered in this study; hence the results are not reported in this work. All the tests illustrated a significant classification capability $(\alpha<0.05)$. Subsequently, DA conducted classification after all the tests' assumptions was met and confusion matrices were then derived from the cross-validated classification results. DA classifications were performed in XLSTAT.

\subsection{Accuracy assessment}

To conduct land cover classification accuracy assessment, we used quantity disagreement and allocation disagreement techniques. Quantity disagreement involves the sum of the least perfect matches between the training (70\%) and the testing $(30 \%)$ datasets of each land cover type. The quantity disagreement follows when the column total of a land cover class deviates from the row total of that class in a confusion matrix. The remainder of disagreement is allocation disagreement. To calculate the agreement between the training and testing datasets, we subtract the two disagreements from $100 \%$. In order to compare the correct land cover classes allocated by DA and to compute overall accuracy, confusion matrices generated following section 2.4.2 were used.

\subsection{Changes in the spatial extent of land cover types}

We quantified the area occupied by each land cover type for the entire study period and expressed it as a proportion of the entire study area. This enabled a comparison and evaluation of land cover changes within the time periods of 1973-1981, 1981-1994, 1994-1998, 1998-2008, 2008-2009 and 2009-2014. We also assess whether there was an association between land cover changes around the lake and the area occupied by water hyacinth in Lake Chivero. A test of proportions was conducted, in S-Plus version 8 software, to test if there were significant changes in the areal extent of the land cover types in the studied period.

\section{Results}

The ANOVA test was used to assess the differences between water hyacinth and other land cover types (Fig. 2). The results demonstrated significant differences $(\alpha<0.01)$ between water hyacinth and other land covers. For the year 1973, 1981, 1994, 2008 and 2009 images, the post hoc test showed that water hyacinth could be successfully discriminated from other land cover types, using Landsat bands 4, 5, 6 and 7.

Fig. 3 shows the derived land cover types, including water hyacinth between 1973 and 2014. It can be observed that in the year 1973 the distribution of shrublands/indigenous forest was more dominant than other land cover types. Between 1973 and 1981, the urban area was proportionally small, but between 1981 and 1994, a significant increase can be noted. From the year 1998 and 2014, the results indicate that the distribution of built-up areas increased and later declined. The distribution of water hyacinth was relatively limited to small spatial extents located at the mouth of the lake in 1973. In 1994 water hyacinth increased its distribution, and later decreased in the year 2008 and 2009 , limited occurrence along the banks of the lake Based on our data, in 1981 and 1998 no water hyacinth was detected, however, this may be attributed to classification model error.

The results showed high classification accuracies, with maximums of $84 \%$ (1981) and minimums of $17 \%$ (1998) (Fig. 4). It can be observed that the agreement across land cover types is higher than the 

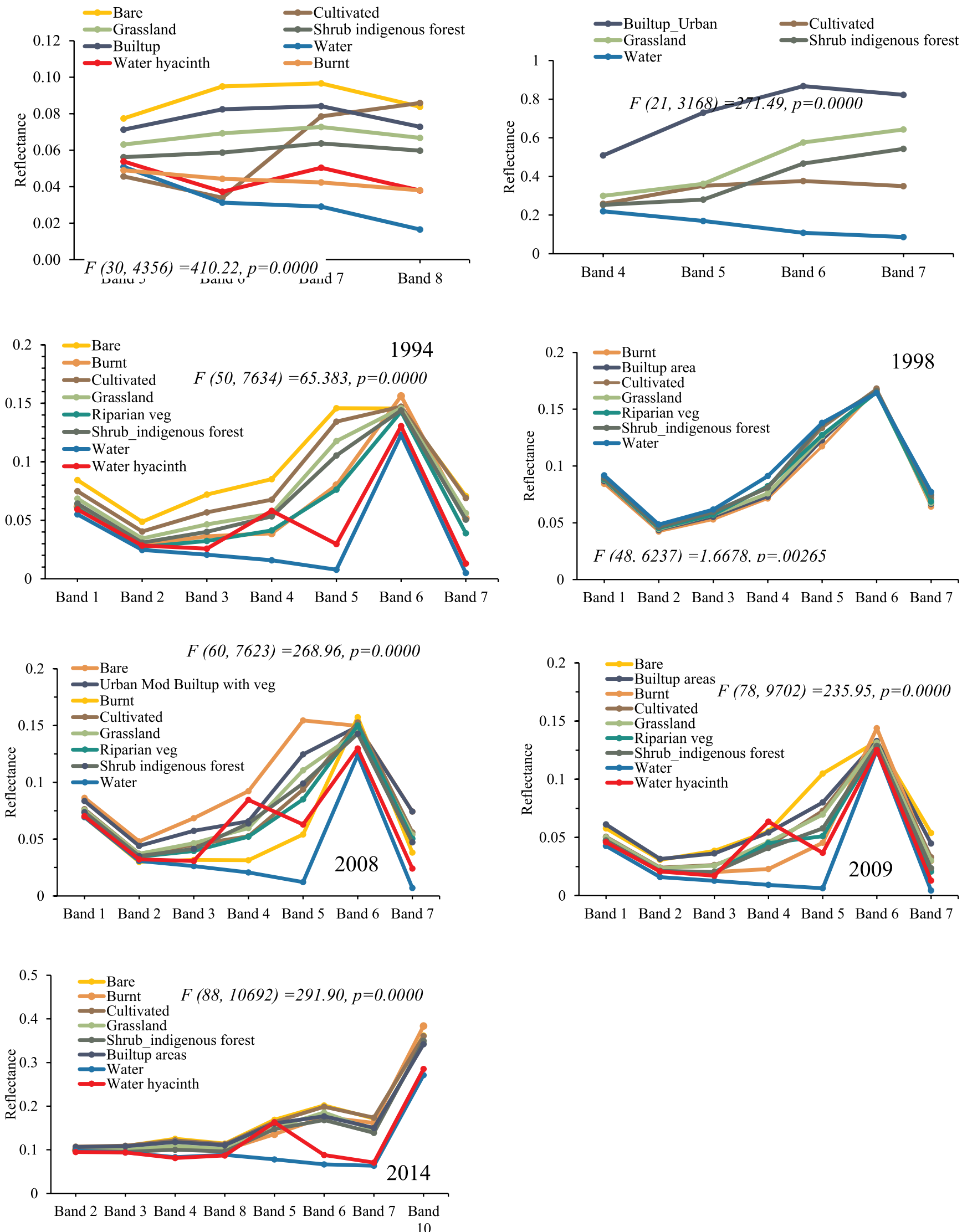

Fig. 2. Derived land cover spectral profiles for the year (a) 1973, (b) 1981, (c) 1994, (d) 1998, (e) 2008, (f) 2009 and (g) 2014. 


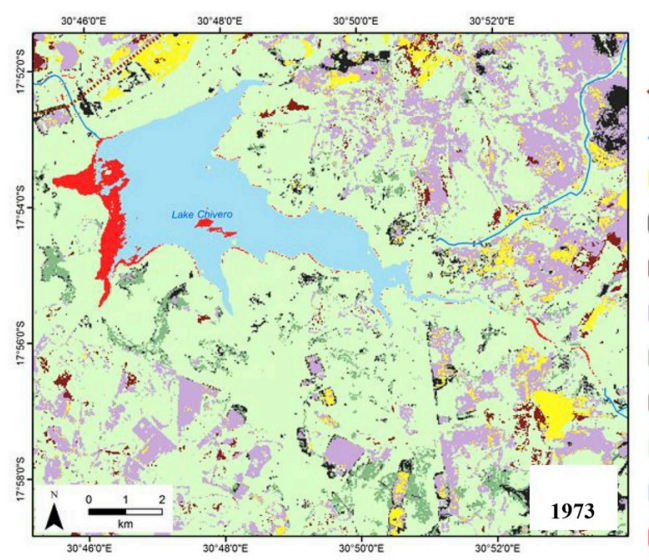

Legend

$\because \cdots *$ Roads

$\sim$ Rivers

Bare

Built-up areas

Burnt areas

Cultivated

Grassland

Riparian \& other veg.

Shrub/indigenous forest

Water

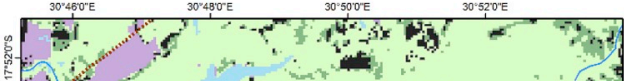

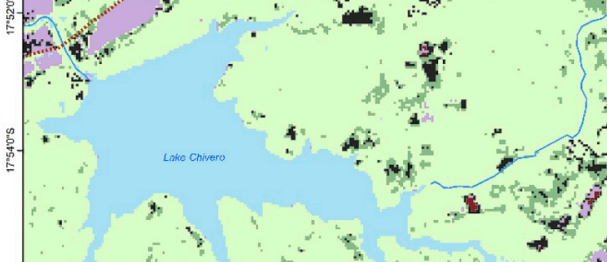

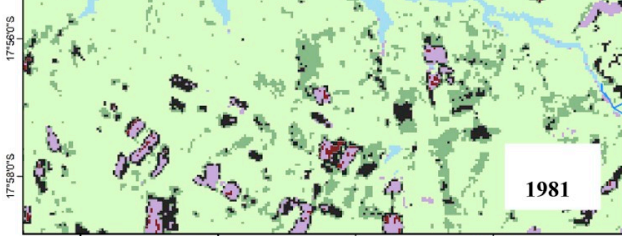
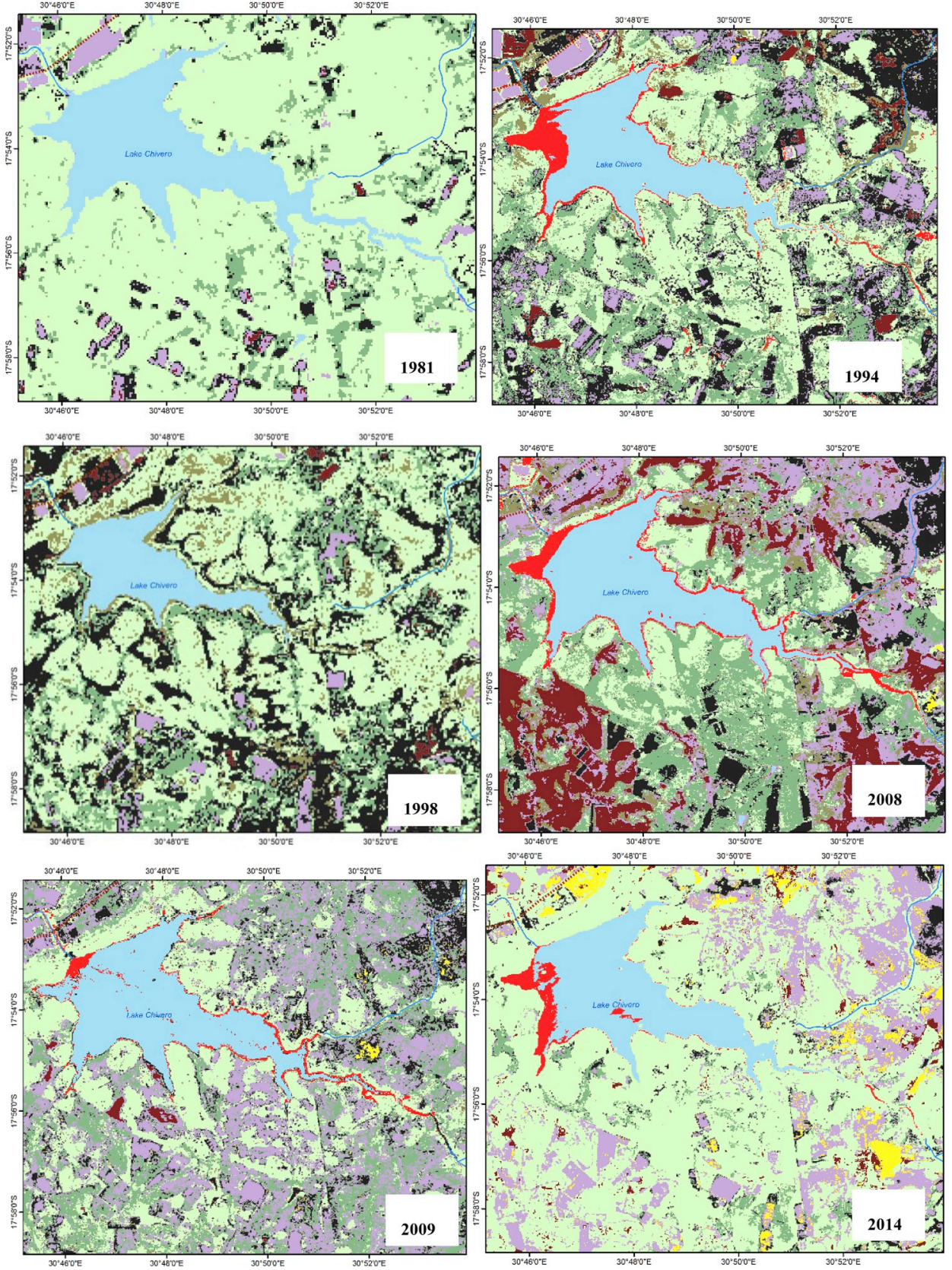

Fig. 3. Thematic land cover maps for the entire period of study. 


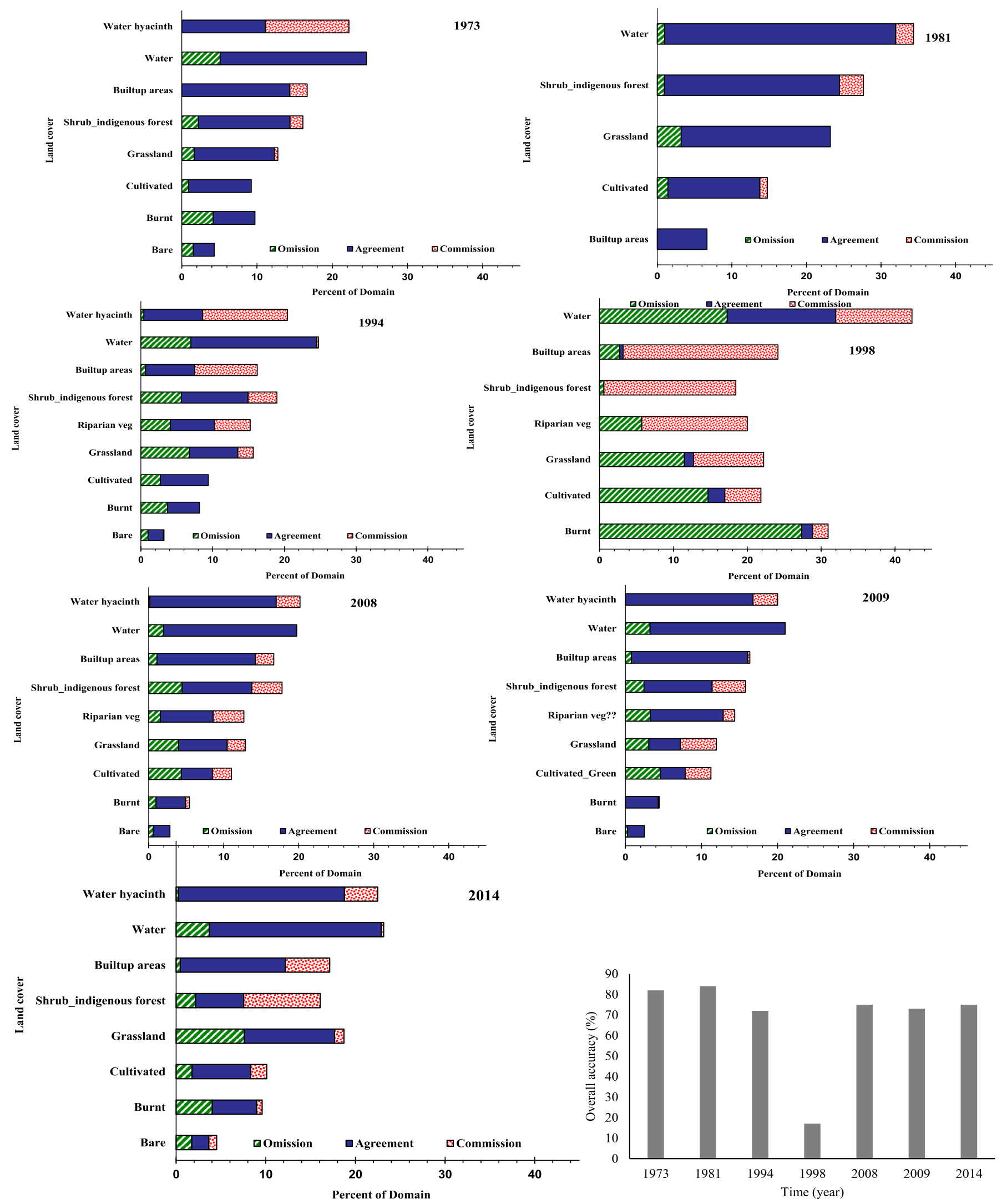

Fig. 4. Derived classification and overall accuracies.

combined omission and commission for most of the years, except for 1994 and 1998, also for the water hyacinth.

Fig. 5 show the area occupied by each land cover type based on each image date. In 1973 and 1981 shrubs and indigenous forests had the highest area in relation to other land cover types. However, a sharp declination was observed in 1994 and 2008, except for the year 1998 was a slight improvement was observed. In the year 2009 and 2014 fast recovery was observed. Cultivated areas increased mostly during the 


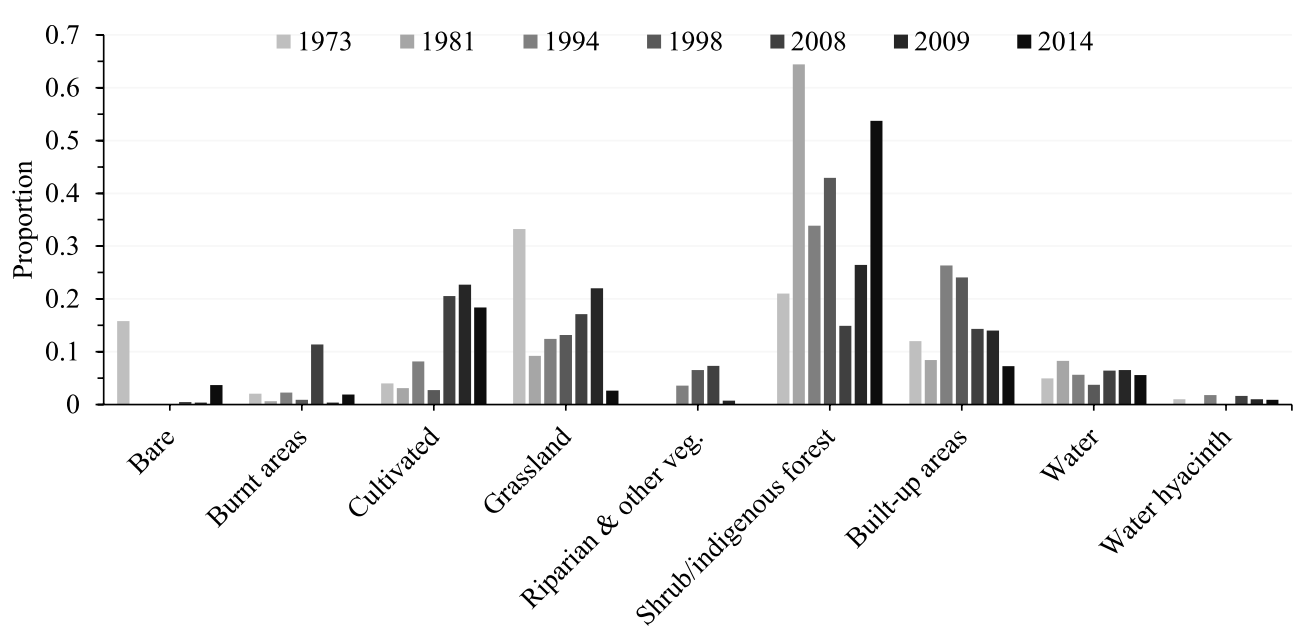

Fig. 5. Variations in the area occupied by different land cover types over the entire period under study.
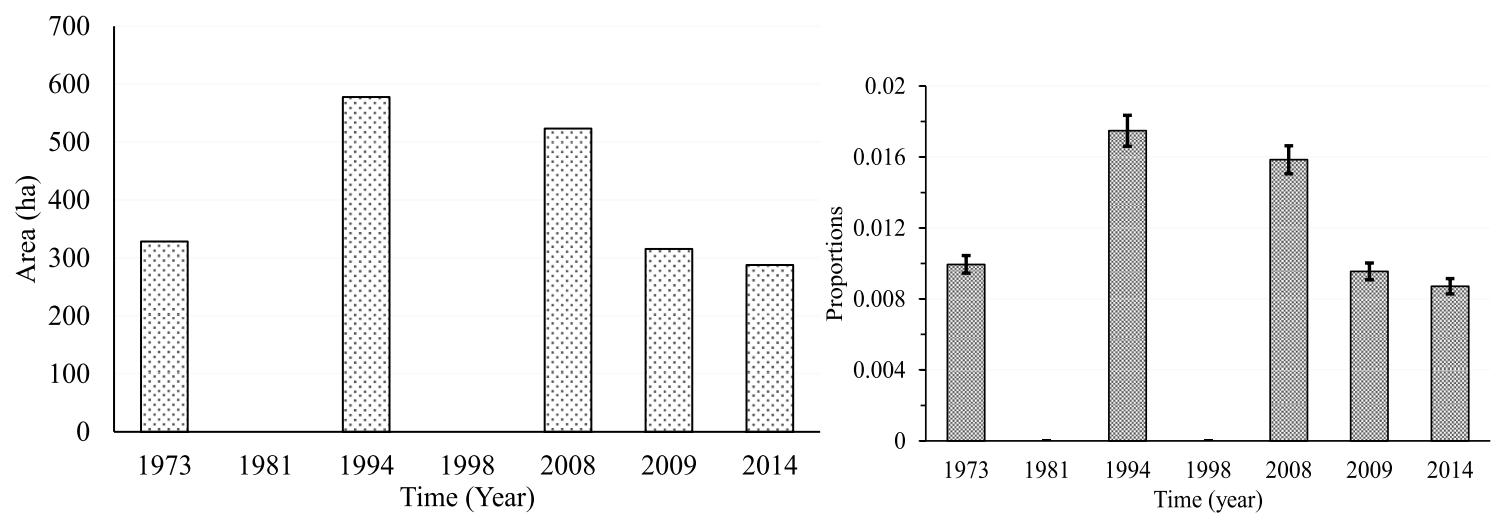

Fig. 6. Significant differences $(\alpha=0.05)$ in the area occupied by water hyacinth between the year 1973 and 2014 .

period between 2008 and 2009. Urban areas were proportionally smaller than other land cover types between 1973 and 1981, with a significant increase from 1994 to 1981 , decreasing in the year 2008, 2009 and 2014. Water hyacinth gradually decreased between 2008 and 2014 (Fig. 6a), with significant differences $(\alpha=0.05)$ in the proportion of area occupied by them during the study period (Fig. 6b).

\section{Discussion}

Continuous, accurate and reliable land use and land cover change information is central to providing guidance to policymakers and urban managers' decisions and to develop effective land use planning and environment conservation strategies. The aim of this study was to establish the link between land cover - land use changes and urban growth in Harare metropolitan (Zimbabwe), between 1973 and 2014, using Landsat satellite series data. This work produced the first updated thematic land cover maps for the city of Harare (Zimbabwe). The results can be used as baseline information for future land cover assessments and planning purposes.

Landsat series provides key information to understand Earth ecosystems and how they respond to natural and human-induced changes, improving their monitoring and maintenance. Due to the sensor spatial resolution $(30 \mathrm{~m})$, it was possible to map the complex urban land cover dynamics based on each land cover spectral properties. The study demonstrated that bands 4, 5, 6 and 7 of the Landsat series data can be used to successfully map urban land cover change dynamics. Results based on these spectral bands showed that continued land conversion for urban, industrial, agricultural and recreational purposes, fragment the previous intact ecosystems and vice versa.

Land use and land cover change dynamics observed in this study reveal that the area has been subject to different changes over time. Changing patterns around the city have transformed the landscape from naturally vegetated areas spread between the hydrological channels to residential, commercial and recreational areas and vice versa. The derived thematic maps show that agricultural land increased from $2 \%$ of the area in 1973 to $30 \%$ in 2014 whereas built up areas decreased in the late 1990 s and early 2000.

During the year 1973, the spatial distribution of forests around Harare was more dominant than other land cover types. In the year 1981 and 1994, a significant increase in the built-up area was observed. This trend can is associated with an increase in the urban population illustrated in Fig. 6 based on the World Bank statistics (https://data. worldbank.org). For instance, in 1981 the urban population was sitting at $23 \%$ of the total population and it increased to $31 \%$ in 1994 (Fig. 7). These trends could be attributed to the colonial settlements bylaws that restricted urban areas to white communities, while black people were restricted to rural areas (Zinyama and Whitlow, 1986). From an environmental perspective, this resulted in less pressure on the environment e.g. natural forest and on freshwater ecosystems. However, soon after Zimbabwean independence in 1980 a sudden decrease in forested areas and an increase in settlements and farmlands can be observed (Moyo, 2000; Sibanda et al., 2016; Zinyama and Whitlow, 1986). This is attributed to the changes in the country government, which resulted in the freedom of movement between rural and urban areas, with no restrictions on the basis of colour. Thus, people started to migrate from rural areas to the cities, increasing the demand for infrastructures, land for settlements and agriculture, energy and water supplies, resulting in a visible clearance of the formerly intact forested areas of these period images. Consequently, these changes resulted in increased pressure on the environment, as well as on urban services delivery and waste 


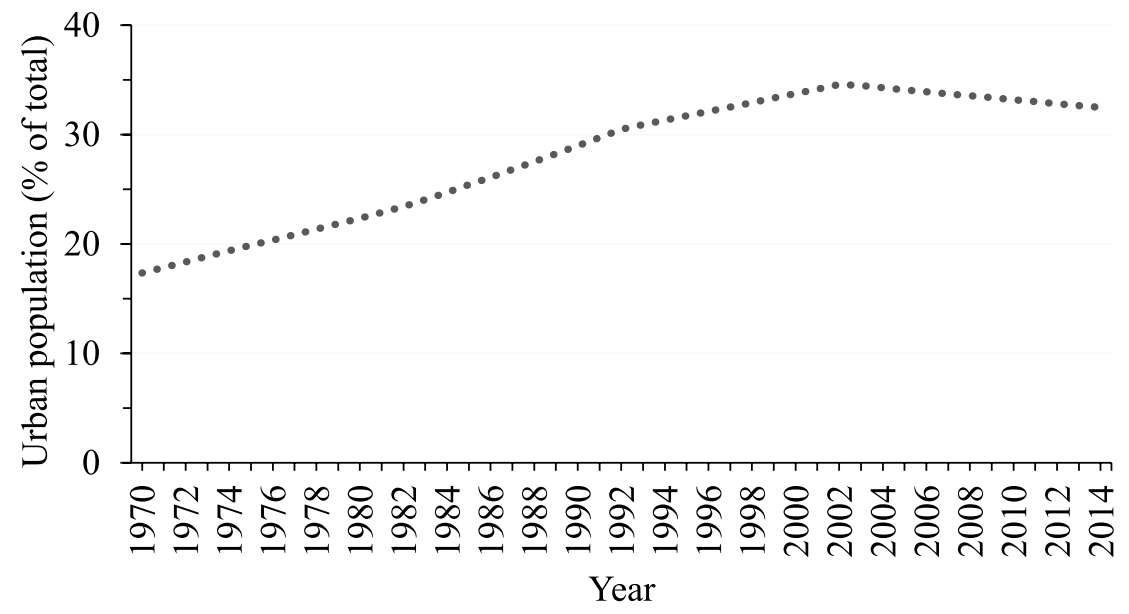

Fig. 7. Urban population increase in Zimbabwe between the periods of 1970-2014 (Source: https://data.worldbank.org).

management practices.

Water hyacinth increased from an areal extent of 350 ha in 1973 to about 550 ha in 1994, may be due to high organic pollution draining into the lake. Then after it slightly decreased between 1994 and 2008. In the year 1973 water hyacinth was relatively limited to small areas located in the mouth of the lake (Chawira et al., 2013; Nhapi, 2009). Literature shows that the lake was invaded by water hyacinth, Eichhornia crassipes during the early 1970s, where it was classified as hypereutrophic with extensive algal and macrophytic infestations and deoxygenation (Chawira et al., 2013; Nhapi, 2009). Meanwhile, the comparatively high rates of water hyacinth during 2008 can be associated with the economic meltdown in Zimbabwe between the year 2000 and 2008. The economic meltdown led to poor waste and sewage management practices, resulting in the nutrient concentration rising in the surrounding freshwater ecosystems leading to eutrophication (Nhapi, 2009).

\section{Conclusions and future work}

The results have shown that:

i. Landsat series data can detect land use and land cover dynamics and possible impacts on freshwater ecosystems.

ii. Derived thematic maps show that for the Harare Metropolitan City, agricultural land increased from $2 \%$ of the area in 1973 to $5 \%$ in 1981, to $30 \%$ in 2014. The city size increased from 1973 to 1994 and decreased the years after (1998 and 2004).

iii. Water hyacinth increased with an increase in urban growth, especially between the year 1981 and 1994, as well as 1994 and 2014.

iv. Landsat bands 4 (0.630-0.680), 5 (0.845-0.885), 6 (1.560-1.660) and $7(2.100-2.300)$ can be used to successfully map land cover changes and this could be attributed to the sensitivity of these bands to subtle vegetation properties.

The Landsat series data offers unique, valuable and reliable historical and current information, required for a successful monitoring of land cover and land use change dynamics. This information can be used as baseline information for future land cover assessment and planning purposes. However, future work is needed to better capture the changes in the city by increasing the number of images over the period. Overall, the study provides new insights on water hyacinth spatial growth dynamics over the years and agricultural expansion in freshwater ecosystems surrounding urban areas in medium-size settlements.
Appendix A. Supplementary data

Supplementary data to this article can be found online at https:// doi.org/10.1016/j.pce.2018.09.010.

\section{References}

Adam, E., Mutanga, O., Odindi, J., Abdel-Rahman, E.M., 2014. Land-use/cover classification in a heterogeneous coastal landscape using RapidEye imagery: evaluating the performance of random forest and support vector machines classifiers. Int. J. Rem. Sens. 35 (10), 3440-3458.

Bhattacharya, A., Romani, M., Stern, N., 2012. Infrastructure for development: meeting the challenge. In: Centre for Climate Change Economics and Policy, Londres, . www. cccep.ac.uk/Publications/Policy/docs/PP-infrastructure-for-development-meetingthe-challenge. pdf Consultado el (vol. 15).

Booth, G.L., Creatore, M.I., Moineddin, R., Gozdyra, P., Weyman, J.T., Matheson, F.I., Glazier, R.H., 2013. Unwalkable neighborhoods, poverty, and the risk of diabetes among recent immigrants to Canada compared with long-term residents. Diabetes Care 36 (2), 302-308.

Caldwell, J.C., 1969. African Rural-urban Migration. The Movement to Ghana's Towns. African Rural-urban Migration. The Movement to Ghana's Towns.

Carlson, T.N., Arthur, S.T., 2000. The impact of land use-land cover changes due to urbanization on surface microclimate and hydrology: a satellite perspective. Global Planet. Change 25 (1), 49-65.

Chander, G., Markham, B.L., Helder, D.L., 2009. Summary of current radiometric calibration coefficients for Landsat MSS, TM, ETM +, and EO-1 ALI sensors. Remote Sens. Environ. 113 (5), 893-903.

Chant, S., Datu, K., 2015. Women in cities: prosperity or poverty? A need for multidimensional and multi-spatial analysis. In: The City in Urban Poverty. Springer, pp. 39-63.

Chawira, M., Dube, T., Gumindoga, W., 2013. Remote sensing based water quality monitoring in Chivero and Manyame lakes of Zimbabwe. Phys. Chem. Earth, Parts A/ B/C 66, 38-44.

Chen, M., Liu, W., Tao, X., 2013. Evolution and assessment on China's urbanization 1960-2010: under-urbanization or over-urbanization? Habitat Int. 38, 25-33.

Clark, M.L., Aide, T.M., Grau, H.R., Riner, G., 2010. A scalable approach to mapping annual land cover at $250 \mathrm{~m}$ using MODIS time series data: a case study in the Dry Chaco ecoregion of South America. Remote Sens. Environ. 114 (11), 2816-2832.

Cohen, B., 2006. Urbanization in developing countries: current trends, future projections, and key challenges for sustainability. Technol. Soc. 28 (1-2), 63-80.

Dlamini, S., Nhapi, I., Gumindoga, W., Nhiwatiwa, T., \& Dube, T. Assessing the feasibility of integrating remote sensing and in-situ measurements in monitoring water quality status of Lake Chivero, Zimbabwe. Phys. Chem. Earth, (Parts A/B/C).

Dube, T., Gumindoga, W., Chawira, M., 2014. Detection of land cover changes around Lake Mutirikwi, Zimbabwe, based on traditional remote sensing image classification techniques. Afr. J. Aquat. Sci. 39 (1), 89-95.

Duque, J.C., Patino, J.E., Ruiz, L.A., Pardo-Pascual, J.E., 2015. Measuring intra-urban poverty using land cover and texture metrics derived from remote sensing data. Landsc. Urban Plann. 135, 11-21.

Fields, G.S., 1975. Rural-urban migration, urban unemployment and underemployment, and job-search activity in LDCs. J. Dev. Econ. 2 (2), 165-187.

Gaidzanwa, R.B., 2016. Women and Land in Zimbabwe: State, Democracy and Gender Issues in Evolving Livelihoods and Land Regimes. State, Land and Democracy in Southern Africa, vol 149.

Gumindoga, W., Rientjes, T., Shekede, M.D., Rwasoka, D.T., Nhapi, I., Haile, A.T., 2014 Hydrological impacts of urbanization of two catchments in Harare, Zimbabwe. Rem. Sens. 6 (12), 12544-12574.

Hestir, E.L., Khanna, S., Andrew, M.E., Santos, M.J., Viers, J.H., Greenberg, J.A., Rajapakse, S.S., Ustin, S.L., 2008. Identification of invasive vegetation using 
hyperspectral remote sensing in the California Delta ecosystem. Remote Sens. Environ. 112 (11), 4034-4047.

Kibena, J., Nhapi, I., Gumindoga, W., 2014. Assessing the relationship between water quality parameters and changes in landuse patterns in the Upper Manyame River, Zimbabwe. Phys. Chem. Earth, Parts A/B/C 67-69, 153-163.

Langner, A., Miettinen, J., Siegert, F., 2007. Land cover change 2002-2005 in Borneo and the role of fire derived from MODIS imagery. Global Change Biol. 13 (11) 2329-2340.

Loveland, T., Merchant, J., Brown, J., Ohlen, D., 1991. Development of a land-cover characteristics database for the conterminous U. S. Photogramm. Eng. Rem. Sens. 57 (11), 1453-1463.

Masamba, W.R., Mazvimavi, D., 2008. Impact on water quality of land uses along Thamalakane-Boteti River: an outlet of the Okavango Delta. Phys. Chem. Earth, Parts A/B/C 33 (8), 687-694.

Mberu, B.U., 2016. African migration and population distribution: recent trends, methodological challenges and policy issues. In: International Handbook of Migration and Population Distribution. Springer, pp. 245-267.

Moyo, S., 2000. The political economy of land acquisition and redistribution in Zimbabwe, 1990-1999. J. South Afr. Stud. 26 (1), 5-28.

Muchadenyika, D., Williams, J.J., 2016. Social change: urban governance and urbanization in Zimbabwe. In: Urban Forum. Springer, pp. 1-22.

Mushore, T.D., Mutanga, O., Odindi, J., Dube, T., 2016. Assessing the potential of integrated Landsat 8 thermal bands, with the traditional reflective bands and derived vegetation indices in classifying urban landscapes. Geocarto Int. 1-34.

Nhapi, I., 2009. The water situation in Harare, Zimbabwe: a policy and managemen problem. Water Pol. 11 (2), 221-235.

Odindi, J., Bangamwabo, V., Mutanga, O., 2015. Assessing the value of urban green spaces in mitigating multi-seasonal urban heat using MODIS Land Surface Temperature (LST) and Landsat 8 data. Int. J. Environ. Res. 9 (1), 9-18.

Odindi, J., Mhangara, P., Kakembo, V., 2012. Remote sensing land-cover change in Port Elizabeth during South Africa's democratic transition. South Afr. J. Sci. 108 (5-6), $60-66$.

Palamuleni, L.G., Ndomba, P.M., Annegarn, H.J., 2011. Evaluating land cover change and its impact on hydrological regime in Upper Shire river catchment, Malawi. Reg. Environ. Change 11 (4), 845-855.
Parochetti, J., Arsenovic, M., Getsinger, K., Stubbs, D., Haller, W., 2008. Herbicides for Aquatic Weeds: Addressing the Need for Herbicides for Aquatic Weeds in Irrigation Water in the US. Out look on Pest Management.

Pons, X., Pesquer, L., Cristóbal, J., González-Guerrero, O., 2014. Automatic and improved radiometric correction of Landsat imagery using reference values from MODIS surface reflectance images. Int. J. Appl. Earth Obs. Geoinf. 33, 243-254.

Pons, X., Solé-Sugrañes, L., 1994. A simple radiometric correction model to improve automatic mapping of vegetation from multispectral satellite data. Remote Sens. Environ. 48 (2), 191-204.

Satterthwaite, D., 2003. The Millennium Development Goals and urban poverty reduction: great expectations and nonsense statistics. Environ. Urbanization 15 (2), 179-190.

Shekede, M., Kusangaya, S., Schmidt, K., 2008. Spatio-temporal variations of aquatic weeds abundance and coverage in Lake Chivero, Zimbabwe. Phys. Chem. Earth, Parts A/B/C 33 (8), 714-721.

Shoko, C., Clark, D., Mengistu, M., Dube, T., Bulcock, H., 2015. Effect of spatial resolution on remote sensing estimation of total evaporation in the uMngeni catchment, South Africa. J. Appl. Remote Sens. 9 095997-095921.

Shoko, C., Clark, D.J., Mengistu, M.G., Bulcock, H., Dube, T., 2016. Estimating spatial variations of total evaporation using multispectral sensors within the uMngeni catchment, South Africa. Geocarto Int. 31 (3), 256-277.

Sibanda, M., Dube, T., Mubango, T., Shoko, C., 2016. The utility of earth observation technologies in understanding impacts of land reform in the eastern region of Zimbabwe. J. Land Use Sci. 11 (4), 384-400.

Tacoli, C., McGranahan, G., Satterthwaite, D., 2015. Urbanisation, Rural-urban Migration and Urban Poverty. IIED, London.

Von Braun, J., 2007. The world food situation: new driving forces and required actions. Intl. Food Policy Res. Inst. 18.

Wear, D.N., Turner, M.G., Naiman, R.J., 1998. Land cover along an urban-rural gradient: implications for water quality. Ecol. Appl. 8 (3), 619-630.

Wu, K.-y., Ye, X.-y., Qi, Z.-f., Zhang, H., 2013. Impacts of land use/land cover change and socioeconomic development on regional ecosystem services: the case of fast-growing Hangzhou metropolitan area, China. Cities 31, 276-284.

Zinyama, L., Whitlow, R., 1986. Changing patterns of population distribution in Zimbabwe. Geojournal 13 (4), 365-384. 